\title{
Study of technologies and processes in shipbuilding industry
}

\author{
Faisal S. Al Amri ${ }^{*}$ \\ Saudi Aramco oil company, Marine Terminal Operation Division, Saudi Arabia \\ Received 12 Nov 2017, Accepted 27 Jan 2018, Available online 30 Jan 2018, Vol.6 (Jan/Feb 2018 issue)
}

\begin{abstract}
Shipbuilding industry is an important and strategic industry. The global shipbuilding industry has been dominated by Asian countries (China, Korea and Japan). Metal Processing technologies used on the steel are (straightening, shotblasting, priming) marking, forming, cutting and welding. As will to recognize the common materials-handling and cranes multi-loads to be used in shipyard. The methodology of determination for the shipyard location factors is presented in the current work. It was determined most of the factors. Some may not be important for some countries or facilities. The selected layouts exhibit forms and arrangements of shipyards. Then, mentioned the layout planning method which will effect on competitiveness and productivity. From the studies and experiences it emerged that the product work breakdown structure "PWBS" and Group Technology improves the production and the Quality of the shipbuilding industry.
\end{abstract}

Keywords: Shipbuilding industry, Shipbuilding stages, Types of shipyards, Shipyard layouts

\section{Introduction}

In the $20^{\text {th }}$ century, shipbuilding which encompasses the shipyards, the marine equipment manufacturers and many related service and knowledge providers grew as an important and strategic industry in number of countries around the world. This importance stems from:

- The large number of skilled workers required directly by the shipyard, along with supporting industries such as steel mills, and engine manufacturers.

- A nation's need to manufacture and repair its own navy and vessels that support its primary industries.

Historically, the industry has suffered from the absence of international rules and a tendency towards (statesupported) over-investment due to the fact that shipyards offer a wide range of technologies, employ a significant number of workers, and generate income as the shipbuilding market is global.

Shipbuilding is therefore an attractive industry for developing nations. Japan used shipbuilding in the 1950s and 1960s to rebuild its industrial structure; South Korea started to make shipbuilding a strategic industry in the 1970s, and China is now in the process of repeating these models with large state-supported investments in this industry.

*Corresponding author's ORCID ID: 0000-0003-4131-0518 DOI: https://doi.org/10.14741/ijmcr.v6i01.10914
As a result, the world shipbuilding market suffers from over-capacities, depressed prices (although the industry experienced a price increase in the period 2003-2005 due to strong demand for new ships which was in excess of actual cost increases), low profit margins, trade distortions and wide spread subsidization [1, 2].

\subsection{World shipbuilding industry}

China is the world's largest shipbuilder as shown in Table 1.The country has been an emerging low-cost, highvolume shipbuilder that overtook South Korea during the 2008-2010 global financial crisis as they won new orders for medium and small-sized container ships $[3,4]$. South Korea's "big three" shipbuilders, Hyundai Heavy Industries, Samsung Heavy Industries, and Daewoo Shipbuilding \& Marine Engineering, dominate the global market for large container ships. As freight rates continue to decline into 2016, production delays, and overcapacity in the industry have led South Korean shipbuilders into financial distress. Consequently, significant market share has been ceded to their Chinese and Japanese rivals [5]. Japan had been the dominant ship building nation from the 1960s through to the end of 1990s but gradually lost its competitive advantage to China and South Korea which had lower wages, strong government backing and cheaper currencies.

The market share of European ship builders began to decline in the 1960s as they lost work to Japan in the same way Japan most recently lost their work to China 97|Int. J. of Multidisciplinary and Current research, Vol.6 (Jan/Feb 2018) 
and South Korea. Over the four years from 2007, the total number of employees in the European shipbuilding industry declined from 150,000 to 115,000 [6].The output of the United States also underwent a similar change [7, 8]

Table 1 World shipbuilding market share by countries

\begin{tabular}{|c|c|c||}
\hline Country & $\begin{array}{c}\text { Completed Gross } \\
\text { tonnage [9] }\end{array}$ & $\begin{array}{c}\text { Market Share by New } \\
\text { Orders [10] }\end{array}$ \\
\hline China & 25,160 & $35 \%$ \\
\hline $\begin{array}{l}\text { South } \\
\text { Korea }\end{array}$ & 23,270 & $21 \%$ \\
\hline Japan & 13,005 & $27 \%$ \\
\hline Others & 5,000 & $17 \%$ \\
\hline
\end{tabular}

\subsection{Shipyard classifications}

Shipyards are places in which the ships are built and repaired. These can be yachts, military vessels, cruise liners or other cargo or passenger ships. Shipyards are associated with building, maintenance and basing activities. Shipyards can be classified, according to their main function into:

- Shipbuilding Yard: shipbuilding yards mainly build new ships, offshore structures, etc.

- Ship Repair Yard: ship repair yards are involved mainly in repair work of ship

- Shipbuilding \& Repair Yard: shipbuilding and repair yards are intended to do both jobs (construction and repair)

- Ships modifications and conversion: They intended to convert between ship types by modifying the construction of ships.

- Ships scraping: They intended to divide the ship components to parts and other machineries components.

Also, shipbuilding yards may be categorized conditionally according to:

- Material used in building the hull (steel, Wood, etc.)

- Size of ship (large size ships, medium size ships, and small vessels or boats)

In addition, shipbuilding yards can be divided, according to the range of cooperation with other shipyards into:

- Shipbuilding yards: in which the hull is constructed on building birth and the outfitting, produced installed.

- Assembly yards: in which fully processed hull blocks obtained from other sources are assembled on a suitable building birth and the out fitting are installed.

\section{Metal process in shipyards}

Metalworking is the process of working with metals to create individual parts, assemblies, or large scale structures used in shipbuilding. The term covers a wide range of work for building of ships. It therefore includes a correspondingly wide range of skills, processes, and tools [11].
Metalworking has evolved from the discovery of various producing ductile metals useful for tools and different processes. Modern metalworking processes can be categorized as material stocking, handling, cleaning, straightening, coating, marking, cutting, forming and welding/joining processes. Today's shipyards include a number of machine tools capable of creating a useful work pieces can be assembled together to make ship blocks $[12,13]$.

\section{Shipbuilding stages}

Shipbuilding stages can be divided into the following:

- Construction stages, and

-Non-Construction stages

\subsection{Construction stages}

Hull construction: The Hull Block Construction Method (HBCM)

Outfitting: The Zone Outfitting Method (ZOFM)

Painting: The Zone Painting Method (ZPTM) as shown in Figure (1), include:

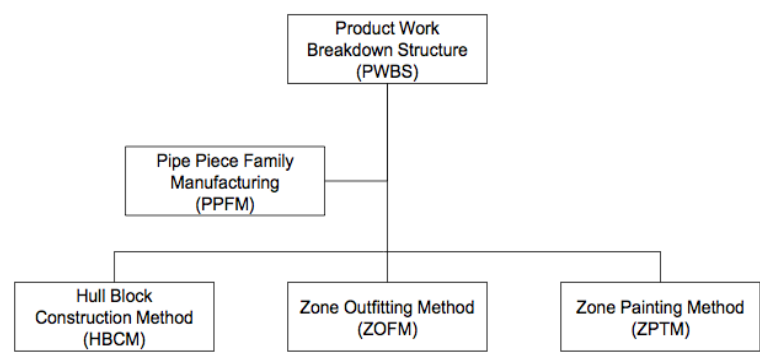

Fig. 1: Integration of different work breakdown structures

3.1.1. Hull Block Construction Method (HBCM) Manufacturing Levels

Level 1 Parts fabrication

Parts fabrication means producing non-sub dividable components and piece parts. The work in this manufacturing level includes marking, cutting and forming.

Level 2 Part Assembly

Parts assembly is building up sections or stiffened panels. The main metal work process in this level is the welding process.

\section{Level 3 Sub-block Assembly}

Sub-assembled structural parts are building up plates with transverses, girders and floors. The metal work process in this level is welding, cutting, marking and grinding

98 | Int. J. of Multidisciplinary and Current research, Vol.6 (Jan/Feb 2018) 


\section{Level 4 Semi-block Assembly}

Semi-block assembly stage is assist to assemble partial zones to main block. The main metal work process in this level is low-bed transporter

\section{Level 5 Block Assembly}

Block assembly which is flat, curved and superstructure blocks as shown in Figure (2). The main work process in this stage is joining and low-bed transporter.

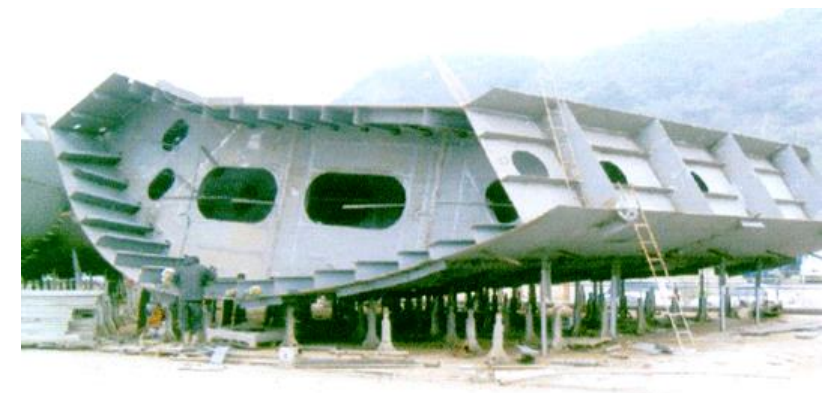

Fig. 2: Example of Block assembly

\section{Level 6 Grand-block Joining}

Grand-block assembly stage is to join semi block assemblies to form a complete block in ship's hull. The main work process in this stage is joining,

\section{Level 6 Hull Erection}

Hull erection is complete hull is considered as a zone included fore hull, aft hull, cargo hold, engine room and superstructure as shown in Figure (3). The main work process in this stage: joining, cranes, coating and painting

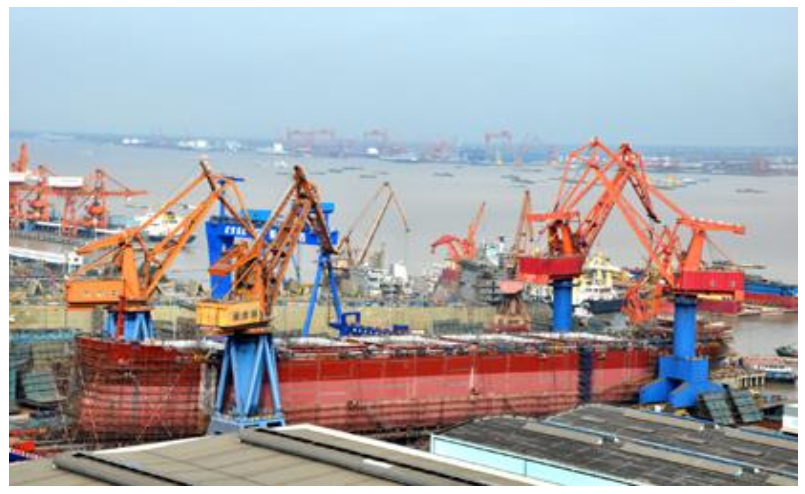

Fig. 3: Example of hull erecting

\subsection{Pre-construction stage}

Shipbuilding is an industry that produces products (ships, offshore structures, floating plants, etc) for customers (private owners, companies, governments, etc.), In most cases, the product is built to order and customized to the specific requirements of the purchaser.
This applies even in cases where a similar series of ships is being built. The entire process is likely to vary somewhat, depending on the customer involved, but it generally involves a number of specific stages. These may be summarized as:

- Development of owner's requirements.

- Preliminary/concept design.

- Contract design.

- Bidding

- Contracting.

- Detail design (post contract design)

- Technological drawing and planning

\subsection{Basic Design of the Ship}

The economic factor is of prime importance in designing a merchant ship. An owner requires a ship which will give him the best possible returns for his initial investment and running costs. This means that the final design should be arrived at taking into account not only present economic considerations, but also those likely to develop within the life of the ship.

With the aid of computers it is possible to make a study of a large number of varying design parameters and to arrive at a ship design which is not only technically feasible but, more importantly, is the most economically efficient.

\subsection{Preparation of the Design}

The initial design of a ship generally proceeds through three stages: concept; preliminary; and contract design. The process of initial design is often illustrated by the design spiral as shown in Figure (4) which indicates that given the objectives of the design, the designer works towards the best solution adjusting and balancing the interrelated parameters.

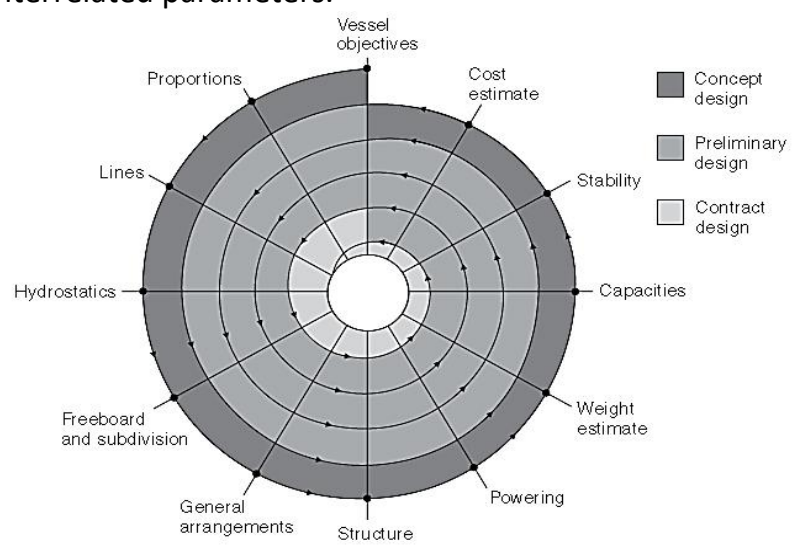

Fig. 4: Ship Design spiral

A concept design should, from the objectives, provide sufficient information for a basic techno-economic assessment of the alternatives to be made. Economic criteria that may be derived for commercial ship designs 99 | Int. J. of Multidisciplinary and Current research, Vol.6 (Jan/Feb 2018) 
and used to measure their profitability are net present value, discounted cash flow or required freight rate. Preliminary design refines and analyses the agreed concept design, fills out the arrangements and structure and aims at optimizing service performance. At this stage the builder should have sufficient information to tender. Contract design details the final arrangements and systems agreed with the owner and satisfy the building contract conditions.

Total design is not complete at this stage, it has only just started, post contract design entails in particular design for production where the structure, outfit and systems are planned in detail to achieve a cost and time effective building cycle. Production of the ship must also be given consideration in the earlier design stages, particularly where it places constraints on the design or can affect costs.

\subsection{Information Provided by Design}

When the preliminary design has been selected the following information is available:

- Dimensions

- Displacement

- Stability

- Propulsive characteristics and hull form

- Preliminary general arrangement

- Principal structural details

Each item of information may be considered in more detail, together with any restraints placed on these items by the ships service or other factors outside the designer's control.

1. The dimensions are primarily influenced by the cargo carrying capacity of the vessel. In the case of the passenger vessel, dimensions are influenced by the height and length of superstructure containing the accommodation. Length where not specified as a maximum should be a minimum consistent with the required speed and hull form. Increase of length produces higher longitudinal bending stresses requiring additional strengthening and a greater displacement for the same cargo weight.

2. Displacement is made up of lightweight plus deadweight. The lightweight is the weight of vessel as built, including boiler water, lubricating oil, and cooling water system. Deadweight is the difference between the lightweight and loaded displacement, i.e. it is the weight of cargo plus weights of fuel, stores, water ballast, fresh water, crew and passengers, and baggage. When carrying weight cargoes (e.g. ore) it is desirable to keep the lightweight as small as possible consistent with adequate strength. Since only cargo weight of the total deadweight is earning capital, other items should be kept to a minimum as long as the vessel fulfills its commitments.

3. In determining the dimensions statically stability is kept in mind in order to ensure that this is sufficient in all possible conditions of loading. Beam and depth are the main influences. Statutory freeboard and sheer are important together with the weight distribution in arranging the vessel's layout.

4. Propulsive performance involves ensuring that the vessel attains the required speeds. The hull form is such that it economically offers a minimum resistance to motion so that a minimum power with economically lightest machinery is installed without losing the specified cargo capacity.

5. The general arrangement is prepared in co-operation with the owner, allowing for standards of accommodation peculiar to that company, also peculiarities of cargo and stowage requirements. Efficient working of the vessel must be kept in mind throughout and compliance with the regulations of the various authorities involved on trade routes must also be taken into account. Some consultation with shipboard employees' representative organizations may also be necessary in the final accommodation arrangements.

6. Almost all vessels will be built to the requirements of a classification society such as Lloyd's Register. The standard of classification specified will determine the structural scantlings and these will be taken out by the shipbuilder.

\subsection{Ship Contracts}

The successful tendering shipbuilder will prepare a building specification for approval by the owner or his representative which will form part of the contract between the two parties and thus have legal status. These technical specifications will normally include the following information:

- Brief description and essential qualities and characteristics of ship.

- Principal dimensions.

- Deadweight, cargo and tank capacities, etc.

- $\quad$ Speed and power requirements.

- Stability requirements.

- Quality and standard of workmanship.

- Survey and certificates.

- Accommodation details.

- Trial conditions.

- Equipment and fittings.

\subsection{Software improves shipbuilding}

Shipbuilding software Marine is composed of integrated design and production products combined with open and flexible lifecycle management solutions that improve design development in floating offshore projects. It covers all design disciplines and facilitates creation and modification of design data.

Shipbuilder software is there to support you to do things right the first time. For the project manager, designer, engineer, production manager or planner, each 
will benefit from the shared and consistent information. Shipbuilder will make the complex information transparent, from concept design to delivery of the ship. So you can do the things right the first time.

\section{Shipyard location and layout}

Environmental, social, and technical factors influence the site location decisions for new shipyards. These factors introduce difficulties for making facility location decisions to establish, to reestablish, or to expand their operations for not only the shipbuilding industry but also any industries. A facility location decision problem encircles the identification of selection criteria, generation of alternatives, analysis of alternatives according to defined criteria, evaluation, and selection among alternatives phases. Power plants, logistic hubs and spokes, warehouses, railway terminals, container ports, and shipyards are adumbrative facilities to be located. In any industrial application, facility selection usually starts with noticing and recognizing a need for additional capacity or a need for relocating available capacity. In today's booming shipping and shipbuilding market conditions, shipbuilding corporations and/or shipbuilding-related firms have been forced to relocate production facilities and/or locate new production facilities to respond to competitors' flexibility and needs and to adapt to rapidly changing conditions, as the total capacity of shipbuilding industry in all over the world increased more than twice since the 1990s. This shipbuilding market condition suggests that new sites for new building shipyards are essential in mid to long term. Thereafter, when the need for new sites has been recognized, factors and sub factors for location selection should be defined in a correct manner. Location selection factors could be qualitative or quantitative. Despite the fact that general industrial facility location decision studies have drawn increased and concentrated attention from both academic and business communities in the past two decades, none of them have tried to define the facility location selection criteria in a systematic way. Above all, it is obvious that almost none of the attention has been taken from the shipbuilding industry's academic and business communities until recently. After this step, the definition and decision of location selection criteria, a search for the best location should be started. Location selection problems have mostly attracted researchers in economics, industrial engineering, and geography [14, 15].

\subsection{Criteria for shipyard location selection}

These main factors have their own sub factors that show the name of the location selection criteria for new building shipyards, the subjective or objective property of the location selection criteria for new building shipyards, the measurement type of the location selection criteria for new building shipyards and by whom it should be measured, and the condition of location selection criteria for new building shipyards as "more is better" or "less is better."

-Road transportation services criteria. The construction of shipyard infrastructure starts by road transportation. Almost all of the small hardware, goods, and so forth for shipyard and shipbuilding issues are transported by road transportation. The network of road transportation is fairly important. The roadway properties are also evaluated in road transportation services criteria.

-Air transportation services criteria. Especially during construction period of ships, urgent light materials and equipment can be air freighted. In addition to that, staff and managers from both parties not only from shipyards but also from owners can reach shipyards

- Maritime transportation services criteria. At first phase, if the construction of a shipyard infrastructure is done by modular concepts then this transportation mode will be efficient. In addition to that, after signing the first contract, heavy load raw materials such as plates and profiles and heavy load equipment such as main engine and generators should preferably be shipped by maritime transportation.

- Electricity power supply possibility criteria. One of the most important things for any industrial facility is the power supply. The equipment for shipyard processes such as cutting, bending, welding, testing, and so forth need a remarkable amount of power.

- Gas supply possibility criteria. Shipyard processes for ship construction need different kinds of gases and/or gas mixtures that depend on the process and the type of raw material. The raw materials could be several types and/or grades such as steel, aluminum, and so forth.

- Precipitation (hydrometeor) criteria. Most of the processes in shipbuilding for instance painting activities are highly affected by weather conditions on site.

- Wind conditions criteria. Most of the shipyards, especially the mid-sized and bigger capacity shipyards have open top slipways, docks, launch ways, and other open facilities. One of the important tasks in shipbuilding is the lifting and turning works of heavy sections and superblocks $[14,15]$.

- Cost of labor criteria. One of the main cost items in shipbuilding is workmanship cost. This cost consists of two main portions: one is the cost of labor per hour and other is taxes. Although the type and complexity of the project influence the total percentage of workmanship cost in the project, the general approach is: $25 \%$ to $29 \%$ of total cost is the cost of labor. The main cost items and the total percentages are presented below as shown in Figure (5) $[16,17]$.

- Quality and price of public natural gas supply criteria. Although this is not a "must" for shipyard activities, the availability of the natural gas supply is an alternative energy resource for the shipyard. The housing development near the shipyard can also benefit from an existing natural gas supply network $[15,17]$. 


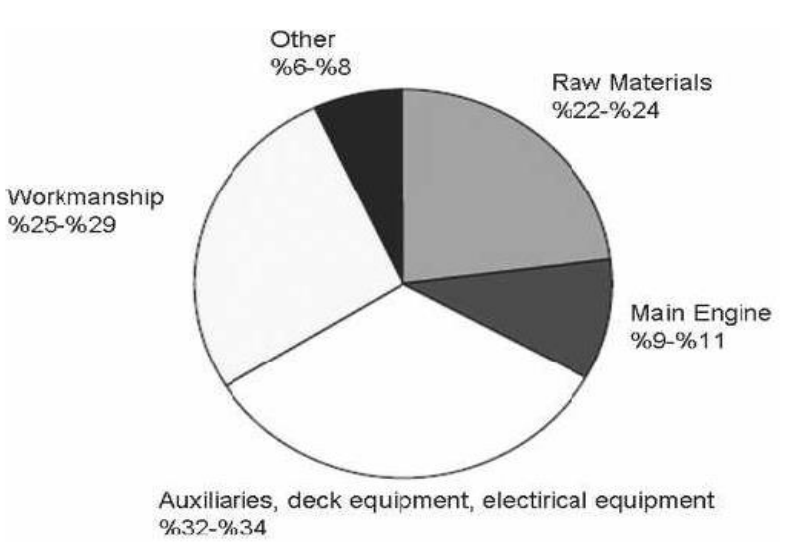

Fig. 5: Pie diagram of percentage of cost items in shipbuilding projects

\subsection{Shipyard Layout}

Facility layout is defined as the arrangement of facilities aimed to achieve the operational objectives of an enterprise at minimum costs and with maximum efficiency. A poor layout can reveal highly detrimental to productivity and consequently to profitability. Symptoms that are peculiar to a poor plant arrangement can be summarized into:

- great travel distances in the flow of materials

- bottlenecks in the shipment of resources

- excessive handling of materials

- poor information circulation

- inefficient communication system

- low rate of machine and labor utilization

Therefore it is primordial to plan a facility layout rather than let it develop according to the prevailing circumstances. It consists of a procedure that thoroughly contemplates all the production processes of the enterprise starting from the material procurement and taking into account the actual prevailing environment. It is expected that such approach will carry some incontestable benefits like optimal utilization of space and equipment, more efficient flow of materials, efficient materials handling, improved production process, better planning system, and work organization flexibility.

\subsubsection{Factors Influencing Yard Layouts}

The layout problem is common to every type of enterprise - from the small retailer to the largest manufacturing industries. The aim of each company is to obtain maximum benefit from their facilities. The adequacy of the layout directly affects the efficiency of the plant.

Principal factors which affect shipyard layouts are briefly discussed below.

\subsubsection{Range of ship types to be built}

Ideally this should be one type, or two types of approximately similar type and size. In the case of one type, this can lead to a rationalization or standardization of design and production process, series production and a high efficiency of output.

Due to fluctuations in world demands for the various types, this ideal case is not often met in practice. Possible exceptions are yards producing vessels such as naval ships or trawlers/small steel craft.

In general, the type of vessels to be built will have considerable bearing upon the basic layout of the yard in respect of their size and various work contents, such as a large proportion of outfitting work in case of passenger and naval ships, or a large proportion of steelwork in case of tankers.

\subsubsection{Space required and available}

The overall area is governed by the space required for the various stages of the building process. Such spaces should be of a size capable of accommodating the proposed flow of materials through them. The size of the various spaces should be such that there is a level workload through the production process. In practice the workload is not level and it is normal to incorporate buffer areas where materials may be stored before moving on to the next stage in the process.

In practice, particularly in existing yard, it is often not possible to allocate the ideal size of spaces which have been mentioned above. In this case it is necessary (by careful production planning, possible reallocation of some areas and changes in basic construction techniques) to improve the flow of material through the various shops.

\subsubsection{Amount of mechanization}

The actual amount of mechanization and automation will depend on the capital expenditure available, the wage level of the area/country and the availability of labor; for example, if labor is cheap and plentiful it may be advantageous to carry out operations manually in preference to using high cost machinery. Alternatively, if there is a shortage of labor, or labor costs are high then it may be preferable to invest in machinery instead.

\subsubsection{Materials handling}

The speed, direction and efficiency of material flow will depend on the type of transportation employed. Ideally, the handling of material should be kept to a minimum.

\subsubsection{Construction methods employed}

Directly related to the foregoing items are the methods of construction employed. The design and construction method should be best suited to the production facilities and vice-versa. For example, the size and layout of the ships, materials handling, etc, will depend on factors such as the amount of pre-fabrication employed, whether flat panel shops are used, the ambient weather which will 
indicate the amount of work to be carried out under cover, etc.

\section{Conclusions}

Shipbuilding is an industry that produces products such as ships, offshore structures, and floating plants for customers; the product is built to order and customized to the specific requirements of the purchaser. This applies even in cases where a similar series of ships is being built. The entire process is likely to vary somewhat, depending on the customer involved, but it generally involves a number of specific stages. The main stages in shipbuilding process are summarized as:

- Development of owner's requirements.

- Preliminary and concept design.

- Contract design.

- Detail design and planning.

- Construction.

The final stage of the shipbuilding process is the actual construction of the vessel. Ship construction can be considered to occur in three manufacturing levels as follows

1) Parts manufacturing, using raw materials such as steel plate and sections, pipe, sheet metal, and cable to manufacture individual parts. The purchasing and handling of components can be considered to be a part of this lowest manufacturing level.

2) The next manufacturing level involves the joining of parts and components to form subassemblies or units. These small collections of joined parts are then combined in the third manufacturing level to form hull blocks. Hull blocks are commonly the largest sections of ships built away from the final building site.

3) Erection, the final manufacturing level, involves the landing and joining of blocks at the building berth.

4) The most important characteristics that distinguish ship building industry that it's an international industry. Ship building industry is an open international market. Anyone who wants to own a ship can get it from anywhere in the world without restrictions. Also, ship building industry is cyclic. There is a limited number of ship-yard in a number of countries which control such industry on international level.

5) Planning and management process in the ship yards are the following:
- $\quad$ organizational process of creating and maintaining a plan

- The psychological process of thinking about the activities required to create a desired goal on some scale.

The physical sites, fixed capital, and labor force of shipyards have a major impact on their productivity. It is accepted generally that the productivity of shipyards is in many cases constrained by their sites and by the yards' inability to effect comprehensive replacement of often obsolete physical facilities.

The shipyard's competitiveness is influenced by the performance of the shipyard. Also, marketing and promotion, product guarantees and in service support, and marine industry infrastructure has a great effect on the competitiveness of the shipyards.

\section{References}

[1] Korean: Korea Marine, \# 1 four years recaptured, English, 2000

[2] Korean Shipbuilders Rank in Top 10". Marinetalk.com. 2006-

01-03. Retrieved 2010-11-17.

[3] Largest shipbuilding nations based on gross tonnage 2015 Ranking". Statista.

[4] http:// www.brs-paris.com/ annual/ annual-2013/ pdf/02newbuilding-a.pdf

[5] www.ft.com.

[6] Zagreb Institute of Public Finance, Newsletter No. 64, December 2011, ISSN 1333-4263

[7] James Brooke (2005-01-06). "Korea reigns in shipbuilding, for now". The New York Times. Retrieved 30 December 2009.

[8] Shipbuilding.or.kr. Retrieved 2010-11-17.

[9] "Largest shipbuilding nations based on gross tonnage 2015 Ranking". Statista.

[10] "Global shipbuilding market by region: contracting 2015 Statistic". Statista.

[11] OECD Council Working Party on Shipbuilding, "Factors affecting the structure of the world shipbuilding industry", OECD Council Working Party on Shipbuilding (WP6), November 2007.

[12] ISO 8686-5: "Cranes; design principles for loads and load combinations; part 5: overhead travelling and portal bridge cranes" (1992)

[13] Eyres D. J., "Ship Construction", Fifth edition, ButterworthHeinemann, 2001, ISBN 0750648872.

[14] Ghosh, A., and Harche, F. Location-allocation models in the private sector: progress, problems, and prospects, Location Science, 1993.

[15] Mount, S. M. Strategic facility planning as a component of the business plan, Industrial Development, 1990.

[16] Thurston C. W., "Priming the Cuban market. (International Coating Scene).(demand for paints and coatings): An article from: Coatings World ", Rodman Publications, Inc., 2005.

[17] Turktermap. Master Plan for Turkish Shipyards, Turkish Undersecretariat for Maritime Affairs, Ankara, 2007. 